\title{
Psychodermatology from the perspective of a psychologist
}

The development of psychosomatics and health psychology contributed to the holistic perception of a patient, and therefore to the origin of psychodermatology. Psychodermatology is a relatively young field of knowledge, which stemmed from dermatology, psychiatry and psychology. The aim of the present article is to: 1) characterize the issues of psychodermatology and systematize knowledge about it, 2) determine the role of psychology in this inter- disciplinary field of knowledge, and 3) draw attention to those aspects of psychodermatology which psychology is particularly focused on.

\section{KEY WORDS}

psychodermatology; psychological aspects of dermatological diseases; adaptation to a dermatological disease 


\section{BACKGROUND}

In recent years there has been growing interest in psychodermatology, both in scientific literature and in various media. It attracts the attention of dermatologists as well as psychiatrists and psychologists. Nevertheless, conducting a review of the different definitions and the ways of understanding the notion of psychodermatology, it is possible to observe that the fact emphasized most frequently is that psychodermatology is the sub-specialty of dermatology concerned with correlations between the skin and the psyche (...), or, alternatively, it is the branch of dermatology having that same scope of interest as psychiatry or, to put it in a different way, concerned with the phenomena situated on the frontier of dermatology and psychiatry (Koo \& Lee, 2003; Mercan \& Kivanç Altunay, 2003; Jafferany, 2010; Rodríguez-Cerdeira, Pera-Grasa, Molares, Isa-Isa, \& Arenas-Guzmán, 2011; Leon, Levin, \& Koo, 2013; Yadav, Narang, \& Kumaran, 2013; Senra \& Wollenberg, 2014). Simultaneously, the same texts provide information about the psychological aspects of dermatological conditions, psychological stress experienced by the affected individuals, the role of emotions or the need of psychotherapy. In addition, most scientific publications are written on the basis of the psychological method; alternatively, publications containing, as one of the key words, the notion of psychodermatology are written with the participation of psychologists, or by the latter themselves (among others, Basińska \& Woźniewicz, 2012; Basińska \& Szymańska, 2013; Janowski, Steuden, \& Bereza, 2014; Janowski, Steuden, \& Bogaczewicz, 2014; Miniszewska, Juczyński, Ograczyk, \& Zalewska, 2013; Miniszewska, Chodkiewicz, Ograczyk, \& Zalewska, 2013).

The objective of this paper is to ensure the systematic character of knowledge about psychodermatology, determining the place of psychology in that interdisciplinary branch of science, and to make it easier to investigate in terms of the issues which are found to be particularly interesting by psychologists.

\section{CORRELATIONS BETWEEN THE PSYCHE AND THE SKIN}

Publications within the field of dermatology emphasize the fact that the skin and the central nervous system are characterized by having the same embryonic origins - they are formed from the ectoderm. The consequence of that is the excretion by the skin and by the nervous system of the same hormones and neurotransmitters that participate in inflammatory and immunological processes, and in reactions to stress and pain. In connection with that, apart from the shared origins, the skin and the nervous system are functionally intertwined with one anoth- er. From the perspective of medicine, the condition of the skin provides information about internal biological processes, for example morbid ones (Walker \& Papadopoulos, 2005). In the literature, it has been claimed that the skin is the external part of the nervous system, or that is the greatest organ of the senses (Luban-Plozza, Pöldinger, Krueger, \& Wasilewski, 1995; Papadopoulos \& Bor, 1999). The stimulation of the skin exerts an influence on the mental and physiological development of the organism. Research within the scope of psychoneuroimmunology proves that stimulation of the skin during childhood is a significant factor influencing the growth, differentiation and maturation of the cells of the central nervous system. Newborns who were receiving stimulation through the sense of touch put on weight more rapidly, and also it was observed in their case that physiological reflexes were more mature (Świrszcz \& Schier, 2002).

The skin co-reacts to a different degree with mental processes through the vegetative system, and changes occurring in it may be the expression of physiologically experienced emotions. It is thought that in the case of psychosomatic conditions of the skin, there occurs the constant readiness of the organism to react to unexpected difficult situations, which trigger emotions resulting in the organism maintaining a permanent and elevated condition of readiness. The medical condition develops when a person is unable to relax the condition of readiness (Januszewski, 2001).

The course and the dynamics of the medical condition of the skin, and the prognosis and treatment of it, may be influenced by psychological factors. In connection with that, stress and strong emotions may be factors triggering or exacerbating the medical condition, or extending the course of it, in the case of, among others: psoriasis, atopic dermatitis, alopecia areata, prurigo nodularis, nettle rash, lichen planus, leucoderma, excessive hyperhidrosis, dyshidrotic pompholyx or recurring herpes (Juszkiewicz-Borowiec, 1999; Rabung, Schmidt, Hüther, \& Schauenburg, 2003).

The skin fulfils important functions, both biological and psychological. The former include isolating a person from the environment and making it possible for them to contact the environment, the expression of emotions (anger, anxiety and shame), receiving stimuli, and aesthetic and sexual functions (Czubalski, 1983; Makowska \& Gmitrowicz, 2014). It is the greatest and most visible organ of the body of a person, whereas the outside appearance influences the way in which a person perceives oneself and this person is perceived by other people; in connection with that, it fulfils a major role in the process of socialization. The skin is perceived in aesthetic terms, which may be generalized, making a person assessed as attractive or unattractive. The quality of the skin 
may be of major importance in terms of coping in social situations, adaptation to fulfilled roles, fulfilling social and professional requirements, and fulfilling personal needs. So as to provide an example, individuals suffering from psoriasis are convinced that they are assessed on the basis of the outside appearance of the skin, and, for that very reason, they frequently avoid meetings which are excessively stressful, or, alternatively, humiliating, for them (Walker $\&$ Papadopoulos, 2005). As Walker and Papadopoulos (2005) emphasized, the visible character of the skin and changes to it mean that dermatoses (unlike the majority of other kinds of medical conditions) are not an issue with which only affected individuals have to cope. Diseases of the skin are therefore connected with numerous challenges in daily functioning.

\section{PSYCHOLOGY IN PSYCHODERMATOLOGY}

In Poland, the first significant publications within the field of psychodermatology were those by psychologists from the Catholic University of Lublin (Janowski, 2006; Steuden \& Janowski, 2000, 2001, 2002; Steuden, Okła, \& Puchalska, 2006). Reviewing the different ways of understanding the notion of psychodermatology, one that deserves attention is that presented by Szepietowski (2011), according to whom "psychodermatology is a comparatively new branch of scientific knowledge situated on the frontier of dermatology, psychology and psychiatry" (p. 9). Another view worth bearing in mind is that of Korabel, Dudek, Jaworek and Wojas-Pelc (2008) emphasizing the fact that it is "the branch of science formed from combining and connecting dermatology with psychiatry and psychology” (p. 244). Makowska and Gmitrowicz (2014) also entitled their paper "Psychodermatology - the frontier of dermatology, psychiatry and psychology" even though in their texts they solely refer to connections between dermatology and psychiatry, emphasizing the fact that, in some countries, psychosomatic medicine is a sub-specialization of psychiatry. To quote
Panconesi (2000, pp. 732-733) psychodermatology is the branch of science concerned with "the relationships between cause and effects, between stressing psychosocial events, emotions, anxiety, and depression on the one hand and disease, somatic in general and cutaneous in particular, on the other hand". In the literature, one may also come across the following names: "psychosomatic dermatology" and "psychocutaneous medicine” (Koblenzer, 1996; Panconesi, 2000). In connection with that, taking into consideration psychology in general, and, in particular, health psychology, in the different ways of understanding psychodermatology seems to be an indispensable thing to do. It is worth remembering that it is health psychology that finds application within the field of health and disease, and that it has somehow "absorbed" the most important achievements of psychosomatic medicine, of behavioural medicine, and also those of medical psychology, and that it is concerned, among other things, with the psychological aspects of diseases (Heszen \& Sęk, 2012). The complexity of the relevant issues makes it clear that there is a vicious circle of psychodermatological disorders, which is perfectly compatible with the area of interests of health psychology (Figure 1) in accordance with the opinion of Pott, Sampogona, and Onnis (2007).

It is also the division of psychodermatological disorders, for example, the one which was presented by Koo and Pham (1992), that indicates the justifiability of taking psychology into consideration in approaching the issues in question. The authors referred to above differentiate: 1) physiopathological disorders (exacerbation of dermatological changes and them becoming more acute is dependent upon the emotional condition of a patient - psoriasis, chronic nettle rash chronic, atopic dermatitis (AD), acne, lichen planus and alopecia areata), 2) primarily psychiatric disorders (mental changes induce dermatological changes - trichotillomania, delusional parasitosis of the skin), and 3) secondarily psychiatric disorders (in which problems of a psychological nature are the result of changes caused by the medical conditions of the skin - anxiety, depression).

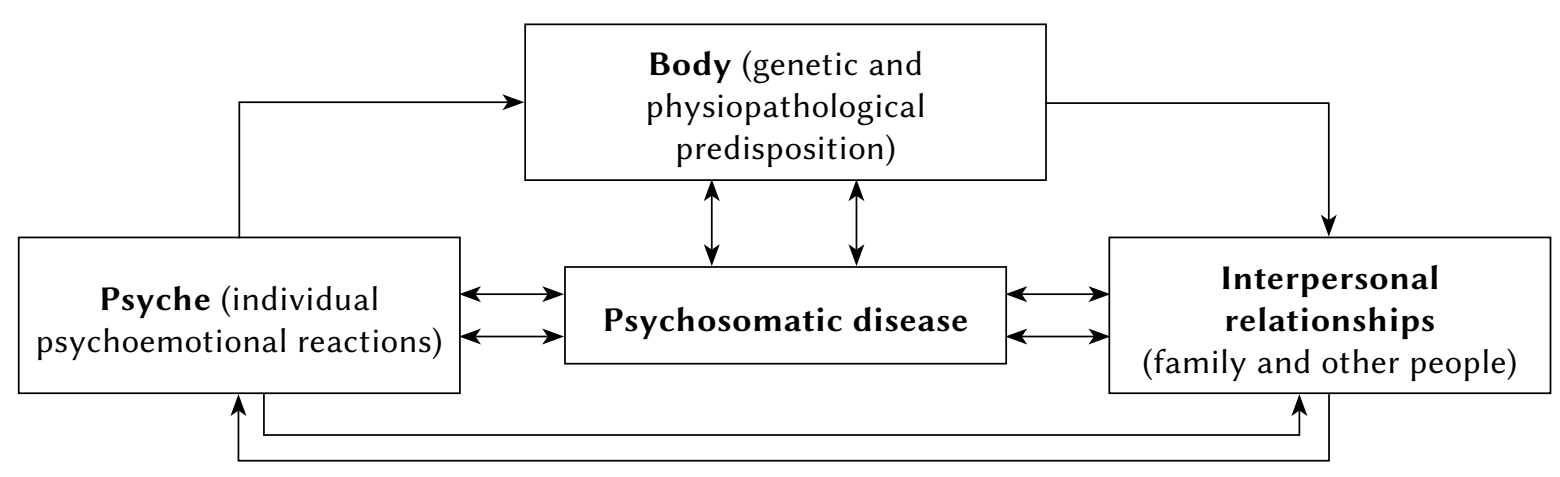

Figure 1. Vicious circle of psychodermatological disorders (figure by author, quoting after Pott, Sampogona, \& Onnis, 2007, p. 228). 
In the course of the analysis of the subject of psychodermatology, and also of papers from that branch of science, it is possible to attempt to present the area of interest of it in a different, roughly sketched way, characterized by an interdisciplinary approach (Figure 2). In such an approach, each of the involved branches of science studies a person suffering from the medical condition of the skin in an autonomous way, restricted to procedures, interventions and knowledge which that branch of science is competent at. To put it in a different way, which is understandable, psychologists and psychiatrists do not claim to be able to conduct the treatment of a somatic condition, whereas a physician dermatologist does not try to substitute for the two former ones in interventions without having consulted them before. Such an interdisciplinary approach seems to be already applied in practice in different medical institutions (Pott et al., 2007; Orion, Feldman, Ronni, \& Ben-Avi, 2012). It is recommendable to apply it in scientific publications unless they represent papers which are written from an interdisciplinary point of view. In addition, it is very important to ensure the flow of information and sharing knowledge amongst individuals involved in such a holistic approach to the affected individual. If that does not occur, it is frequently the case that in medical publications, psychological regularities and methods which have been known and applied for a long time are described as innovative. Furthermore, the results of research obtained by the application of psychological methods are often interpreted incorrectly, whereas conclusions are erroneously generalized.

\section{PSYCHOLOGICAL ASPECTS OF DISEASES OF THE SKIN OVER THE YEARS}

Psychodermatology as a branch of science is a comparatively recent development - it is only in the previous century that the first textbooks of that branch

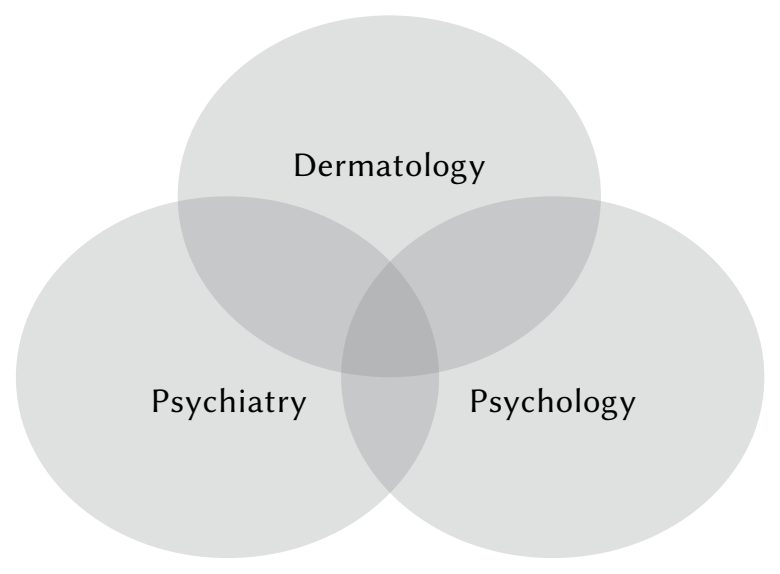

Figure 2. Scope of psychodermatology - own proposal. of science were published (Pott et al., 2007); however, paying attention to the psychological aspects of the medical conditions of the skin is by no means a recent idea - Hippocrates (460-377 B.C.) described the influence of stress on the skin, quoting examples of individuals tearing their hair out in connection with the excessive emotional strain overload (Rodríguez-Cerdeira et al., 2011). The first attempts to take into consideration the role of psychological factors in medical conditions of the skin were made at the turn of the nineteenth and twentieth century, and those are found in the works of such dermatologists as Beard, Tuke, Bukley and Winkler (Papadopoulos \& Bor, 1999). These authors paid attention to certain emotional determinants of diseases of the skin, whereas they did not emphasize the significance of specific psychological problems being the primary cause of the diseases of that type. In 1857, the dermatologist Wilson wrote the book On Diseases of the Skin, in which he described, for the first time, so-called "skin neuroses", among which he included delusional parasitic disease, alopecia areata, pruritus and hypopigmented lesions; he also noted the influence of anxiety and depression on excessive hyperhidrosis (Rodríguez-Cerdeira et al., 2011). In 1925, Joseph Klauder, who was a dermatologist as well, pointed out the justifiability of the application of psychotherapy in individuals suffering from dermatological changes (Rodríguez-Cerdeira et al., 2011).

In the previous century, a fruitless search for patterns of personality and specific emotional conflicts connected with particular medical conditions was commenced. For example, attention was paid to such inappropriate attitudes of the mothers of children suffering from atopic dermatitis (AD), as: transparent, or, alternatively, hidden rejection, hostility towards the child, neglecting it, and a lack of gentleness and physical contact consisting in holding the child and caressing it. The significance of the early discontinuation of breast-feeding of the child as a significant traumatizing factor, or the strong involvement of parents in matters concerning children, constant interference with their life, and also excessive emotional and physical dependency of a child on their parents, were emphasized. Individuals suffering from $\mathrm{AD}$ were described as, among other things, reserved, timorous, shy, emotionally unstable and tense, manifesting problems with coping with feelings of anger and acrimony, and revealing their emotions by means of scratching (Juszkiewicz-Borowiec, 1999; Steuden \& Janowski, 2002; Tuszyńska-Bogucka, Czelej, Lecewicz-Torun, \& Krasowska, 2002). However, in spite of numerous studies, no specific type of personality occurring simultaneously with AD (Świrszcz \& Schier, 2002) was discovered.

Korabel et al. (2008) performed a succinct review of the psychoanalytical conceptions of diseases of the skin, indicating the fact that psychoanalysts such 
as Fenichel, Winnicott and Anzieu put emphasis on interactions between the skin and unconsciousness, trying to explain the connection between dermatological conditions and unconscious conflict. In accordance with the opinion of Pines, eczema appearing in the first years of life is the result of irregularities in the relationships between the mother and the child. The effect of that is difficulties in relationships with other people in the subsequent years of life, which exacerbate the existing problem with the skin. In the case of the lack of access to the awareness of different desires, there occurs the formation of a symptom, which is the partial source of the fulfilment of them, and which, simultaneously, is the source of suffering (Korabel et al., 2008).

Ultimately, attempts to identify particular emotional factors or conflicts connected with dermatoses were abandoned, and attention was concentrated on the assessment of the ways of functioning, of coping, or of adjustment to diseases of the skin. Another popular kind of research is that into the quality of life of the affected individuals, resulting, among other things, in separating the most problematic areas of functioning and factors which influence them (medical, psychological, demographic, etc.). It is emphasized that searching for a single cause of the medical condition is not of much use, and it is solely a holistic approach that makes it possible to understand the problems of the individuals affected by dermatoses better (Papadopoulos \& Bor, 1999; Steuden \& Janowski, 2002; de Korte, Sprangers, Mombers, \& Bos, 2004; Miniszewska et al., 2004; Rodríguez-Cerdeira et al., 2011).

\section{LIVING WITH A MEDICAL CONDITION OF THE SKIN}

Medical conditions of the skin are experienced by those who are affected by them as situations which are difficult, and which cause numerous problems of a psychosocial kind, and that is the very thing that psychology is interested in. Chronic dermatoses, in connection with their recurring character, compel the affected individuals to constantly adjust themselves to changes to their outside appearance. In connection with that, the affected individuals have to learn to cope not only with an outside appearance different from the normal one, but also with the changing image of their own body. In turn, the image of their own body, which is indicated by numerous scientific reports, is closely connected with self-esteem, which, in connection with what is referred to above, is significantly decreased in the case of individuals suffering from medical conditions of the skin (Walker \& Papadopoulos, 2005). In addition, in social awareness, those medical conditions are regarded as contagious, and they are frequently regarded as hav- ing a venereal background; they trigger the feeling of shame. On the other hand, erroneous convictions about the medical conditions of the skin concerning the fact that they are seen as not being a significant problem since they do not result in a direct threat to life, and nor do they influence the daily functioning of a person, are common. Nevertheless, they may cause embarrassment, curiosity, abhorrence or stigmatization, or even as much as discrimination (Pott et al., 2007). It is worth recalling at this point that in the past any departures from outside appearance, in particular, changes on the skin, were treated as a punishment for conducting a sinful life. In the Middle Ages, those affected with psoriasis were under the anathema of the Church, deprived of the right to live in society, or even burnt at the stake as possessed by spirits and impure. Still, in certain regions of the world, it is thought that scars, in particular hairy ones, appear as the result of intimate contacts with the devil or a wild animal. People suffering from diseases of the skin were, for hundreds of years, avoided, punished and regarded as inferior (Papadopoulos \& Bor, 1999; Walker \& Papadopoulos, 2005). Rodríguez-Cerdeira et al. (2011) emphasize that even in the Bible there are references to stigmatizing individuals with changes to the skin - among others, in the Book of Exodus we can find the following passage: "And they took ashes of the furnace, and stood before Pharaoh; and Moses sprinkled it up toward heaven; and it became a boil breaking forth with blains upon man, and upon beast. And the magicians could not stand before Moses because of the boils; for the boil was upon the magicians, and upon all the Egyptians”. In connection with that, it is possible to assume that negative reactions to individuals suffering from dermatological conditions originate indirectly from the conviction that those individuals are directly responsible for their own medical condition (Papadopoulos \& Bor, 1999).

It is also worth emphasizing that not only the psychosocial functioning of individuals struggling against dermatoses is made more difficult - certain medical conditions restrict the activity of the affected individual, make it difficult for them to perform daily activities, exacerbate insomnia, irritation, unrest and embarrassment (Basińska \& Szymańska, 2013; Papadopoulos \& Bor, 1999; Steuden \& Janowski, 2000). Last, but not least, certain dermatological conditions result in disability. Consequently, medical conditions of the skin are themselves the cause of stress, which, afterwards, may result in exacerbation of symptoms, and also in activation of less or more adaptational ways of coping. Apart from that, in the case of certain medical conditions (such as $\mathrm{AD}$ ) emotional strain is revealed by means of scratching, which exacerbates morbid changes. There occurs positive feedback between symptoms and causes, and there appears a vicious circle: a difficult situation - pruritus - scratch- 
ing - irritation of the skin - exacerbation of changes - stress - pruritus (Januszewska, 2001).

Research into the quality of life in medical conditions of the skin indicates that the diseases decreasing the quality of life the most are psoriasis and $\mathrm{AD}$, followed by common acne (Janowski, 2006). The review of the rich literature (de Korte et al., 2004; Janowski, 2006) concerning the issues of the quality of life in psoriasis makes it evident that the influence exerted by those medical conditions on physical functioning is manifested, first and foremost, in feeling pruritus, peeling off and the pain of the skin. The disease makes it difficult to perform such activities as carrying heavy items, walking on stairs, and looking after the household (for example, working in the garden). A problem arises due to the need to wear special clothes, having to change them and to take baths frequently, and due to disturbances in the course of sleep and rest. The psychological functioning of the affected individuals suffering from psoriasis is connected with anxiety, depression, lowered mood, and loss of control over behaviour and emotions. In the case of patients, feelings of shame, helplessness, anger and self-consciousness occur. The medical condition influences the feeling of one's own value and the way of perceiving one's body (including the feeling of being dirty and sexually unattractive). Social functioning means, first and foremost, difficulties in contacts with the surrounding milieu, restrictions in undertaking various kinds of activity (including sexual activity), restricting the possibility of visiting public places, and avoiding situations connected with exposing one's body (attending a swimming pool, sunbathing, going to the hairdresser). Affected individuals avoid wearing clothes not covering the parts of their body affected by morbid changes (for example, in the summer they put on shirts with long sleeves, and trousers rather than shorts); they also avoid wearing dark clothes on which their peeling off skin would be visible. The problems referred to above and concerning social functioning originate from the fear that it is possible that other people will stare at them, from the feeling of embarrassment in connection with the condition of their skin or the feeling of being impure. There are also problems with functioning at the workplace - the studied individuals suffering from psoriasis hold their condition responsible for their being out of work, having to change jobs, or accepting a less attractive position at work (de Korte et al., 2004; Janowski, 2006; Miniszewska et al., 2013).

Chronic, recurrent medical conditions contribute to the feeling of a lack of control, and result in conducting obsessive control of the condition of the skin or compulsive care and hygiene procedures. Apart from that, individuals affected by changes to their skin may additionally blame themselves for their lowered mood and the lack of ability to cope, comparing their condition and situation with those of individuals whose lives are directly endangered (Papadopoulos \& Bor, 1999).

Chronic stress being the consequence of that dermatological condition may manifest itself in the form of various mental disorders. Numerous studies indicate that the occurrence of those disorders amongst patients suffering from dermatoses (both adults and children) is significantly higher than in the general population - approximately $30-60 \%$ of dermatological patients manifests symptoms from the sphere of depressive and anxiety disorders, and also delusional disorders or suicidal thoughts and tendencies (among others, Gieler, 2003; Gupta \& Gupta, 2003; Makowska \& Gmitrowicz, 2014; Picardi, Abeni, Melchi, Puddu, \& Pasquini, 2000; Picardi et al., 2004). A review of the literature concerning mental disorders in dermatological conditions was conducted by Gupta and Gupta (1996) - they found that the most frequently occurring disorders are anxiety disorders, depression, hypochondria and neurotic symptoms, and also problems with expressing emotions. Picardi et al. (2000) found that the frequency of occurrence of mental disorders amongst the patients in the outpatient setting affected by leucoderma was $25 \%$, amongst those suffering from psoriasis $26 \%$, acne $32 \%$, loss of hair $35 \%$, parasitic diseases $27 \%$, and those suffering from nettle rash $34 \%$. In accordance with the opinion of Gupta and Gupta (2001), suicidal thoughts occur in $5.60 \%$ of individuals suffering from acne and in $5.50 \%$ of those suffering from psoriasis. More and more frequently, it is also found that there occur obsessive-compulsive disorders (OCD) in the case of dermatological conditions, or that there are symptoms of OCD, concerning the skin, for example, in acne excoriée (so-called scratching-caused acne).

The risk factors of the occurrence of psychiatric disorders in the case of dermatological patients are: long and frequent stays in hospital, chronic nettle rash, peeling atopic dermatitis of the skin, medical conditions transmitted sexually and receiving medication for long periods of time (medications applied in dermatology - for example, steroids, isotretinoin - may cause mental disorders, whereas medications applied in psychiatric treatment - for example, lithium - may cause changes to the skin). Factors exerting a modifying influence on mental disorders are the kind of medical condition, the extent and situation of changes, their chronicity and duration and sociodemographic variables (Kadri, 2003; Steuden \& Janowski, 2000).

As it was rightly pointed out by Makowska and Gmitrowicz (2014), it is important to assess psychopathology in the case of dermatological patients in a developmental perspective. The skin is a significant organ in terms of communication, and it plays a crucial role in shaping bonds, whereas the earliest social interactions of a newborn child and parent take place by means of physical contact, principally by means of 
touch. The medical conditions of the skin in the period of being a newborn child may contribute to the reduction in the currently experienced stimulus situation, the reduction in natural stimulus simulations, such as massaging or hugging, which is provided for the child at the discussed stage of development by the care provider. Close contact (skin-to-skin touching) is one of the factors determining the development of an emotional bond. Inadequate care within the scope of physical contact at the early stage of development may also result in the manifestation of disorders concerning the perception of one's own body in the further period of life (Makowska \& Gmitrowicz, 2014).

\section{THE INFLUENCE EXERTED BY THE MEDICAL CONDITION OF THE SKIN ON FAMILY MEMBERS}

Dermatological conditions influence the functioning of the entire family as well - that is connected both with treatment (it being necessary to stay at hospital, changing the diet, application of particular preparations) and with restrictions resulting from the somatic condition (for example, it being necessary to avoid the sun, or to avoid staying in public places). The consequence of that may be conflicts, misunderstandings and the feeling of guilt. Some individuals suffering from dermatoses do not want to have children in connection with their fear that the medical condition may be inherited by their offspring (Papadopoulos \& Bor, 1999).

The influence exerted by a medical condition on the family of the patient is particularly noticeable if it is the child that is affected. One of the regularities described in the literature of the subject is starting the vicious circle consisting in the appearance of certain thoughts in the case of parents and as a result of scratching dermatological changes by the child (there is nothing I can do, my child does it on purpose, he was on the wrong kind of diet, I ought to (have) look(ed) after him better), which are the thoughts triggering the feeling of guilt, helplessness, anger and strain. That, in turn, results in punishing, admonishing, increasing control or visiting the doctor more frequently. The consequence of that is the raised level of stress in the case of children, which exacerbates pruritus and scratching (Ehlers, Osen, Wenninger, \& Gieler, 1994).

The dermatological condition of a child may also result in such reactions and attitudes of parents as "parental bereavement", denying the medical condition, shame and the feeling of guilt, an overprotective attitude, concentrating on the needs of the affected child and ignoring the remaining children or, alternatively, rejecting and ignoring the affected child, depression and tiredness (Miniszewska, 2010).

For parents, the medical condition of a child may also be a signal informing them about the loss of so- called "normality", altering the way of perceiving themselves and the conception of family, requiring the change of roles, plans and dreams, and also developing entirely new methods of coping. Research into the parents of children suffering from $\mathrm{AD}$ indicates that the medical condition and outside appearance of a child, and also looking after them, constitute causes of strong stress, resulting in feelings of guilt, frustration, aversion and helplessness (Papadopoulos \& Bor, 1999; Ben-Gashir, Seed, \& Hay, 2004).

\section{ADJUSTMENT TO THE MEDICAL CONDITIONS OF THE SKIN}

Struggling against a dermatological condition is greatly dependent on collaboration with a physician, and on subjecting oneself to the regimen of pharmacological treatment. In that struggle, and in coping with the medical condition, a significant role is played by psychological factors. Adjustment to a dermatological condition depends, among other things, on the course of the medical condition itself (Papadopoulos \& Bor, 1999), and this is the aspect which, together with coping with the medical condition in general, is what health psychology studies. The course may be of a progressive, episodic or acute character. Progressive medical conditions develop in a predictable way. The patients know what they ought to expect, and they are prepared for that. On the other hand, any departures from what is expected by the affected individual may cause strong anxiety (available information about the medical condition is usually very generalized).

Episodic medical conditions are known to go through periods of deterioration or improvement of the state of health. That causes uncertainty and makes it necessary to adjust to the changing outside appearance. Acute medical conditions are short-lasting and predictable. It is possible to keep them under control. However, in certain cases, for example in venereal diseases, social stigmatization becomes a problem (Walker \& Papadopoulos, 2005).

The way of coping with a medical condition also depends on whether the medical condition is congenital or acquired. Congenital medical conditions usually have episodic character; they respond well to treatment, and, in connection with that, they require less adaptational efforts from a patient. In turn, those having long-lasting symptoms require long-term adaptation. In the case of congenital dermatoses, greater adjustment problems are those experienced by parents - the way in which they cope with the medical condition of a child and their attitudes towards that child may influence the way in which the child will cope, and in which they themselves will adjust. The reactions of parents determine the way in which the child will cope with changes to the skin - if those 
reactions are full of anxiety or helplessness, then it is very likely that the child will react in the same way. The parents treating the medical condition of a child as a difficult situation, as a crisis, from which there is no way out, and which requires numerous sacrifices, pass on to the child such a way of perceiving one's own physical condition. In the future, that may result in giving up combating the medical condition, a lack of faith in the remission of symptoms, and decreased motivation to care about one's own skin (Papadopoulos \& Bor, 1999).

A reaction to a congenital medical condition may be anger, the feeling of helplessness, and also accusing parents or other members of the family having those same symptoms. Those affected may perceive their medical condition as a burden resulting from the decrees of fate, or from a misfortune. In such a situation, the affected individual does not feel personally responsible, nor do they blame anyone. Such an attitude is conducive to making it easier to adjust to certain restrictions, which are treated as inconveniencies normal and typical for the family (Papadopoulos \& Bor, 1999).

In the case of acquired diseases, a person is compelled to become accustomed to the "new" outside appearance, to the reactions of other people, and, frequently, to changing lifestyle. If a medical condition is of an unknown aetiology, the affected individual may construct their own convictions concerned with the causes, and the course, of their medical condition, and also undertake behaviours strengthening the conviction that they can control their state of health. Acquired medical conditions may also be the symptom of another medical condition, e.g. Kaposi's sarcoma. In such a situation, an affected individual is compelled to struggle against numerous problems, commencing with the awareness of the fact that their life will be shorter, including physical disability, and changes to outside appearance. Paradoxically, individuals suffering from medical conditions constituting a threat to their lives, which are accompanied by external disfigurement, frequently concentrate, first and foremost, on their outside appearance (Papadopoulos \& Bor, 1999).

Individuals suffering from dermatoses have to go through a period of "psychological adaptation", so as to be able to come to terms with the changes to their body. If they are very disfiguring, or, if they have appeared while one is an adult, the affected individual goes through a period of mourning after the loss of their "normal" outside appearance. The first reaction of them is mourning the loss of it and yearning. The acceptance of the medical condition of the skin is preceded by periods of shock, denial, anger and sadness. In the case of acquired dermatoses, the mourning concerns the image of an individual which might exist in the future (Papadopoulos \& Bor, 1999).

Task-based ways of coping with stress caused by the medical condition of the skin include the follow- ing: maintaining the eye contact with an individual commenting upon outside appearance, responding rapidly to a vicious remark, or redirecting the attention of "the attacker" by means of turning it towards a different aspect. The emotional strategies of coping involve changing the way of thinking and perceiving situations causing anxiety. Their effectiveness depends on the context: in situations in which the affected individual is in control, task-based strategies are more effective, but if they do not have control, emotional ones are more effective (Papadopoulos \& Bor, 1999).

Picardi et al. $(2000,2003)$ point out that affected individuals frequently explain the deteriorating state of their health by stress, whereas their life is not necessarily very stressful. Exaggerating problems makes it possible to find the justification for their own medical condition.

Substantial difficulties with adjustment to changes to the body are experienced by individuals suffering from personality disorders, in particular by individuals suffering from histrionic and narcissistic disorders, in connection with their excessive concentration on visual attractiveness, seeking approval, and excessive sensitivity to the opinions of others. Individuals suffering from borderline disorders perceive the medical condition of the skin as an enormous threat to the image of their body and to autonomy (Ginsburg, 1996).

\section{PSYCHOLOGICAL ASSISTANCE FOR INDIVIDUALS SUFFERING FROM DISEASES OF THE SKIN}

In struggling against severe mental disorders (for example, against deep depression, anxiety disorders, etc.) occurring in the case of individuals suffering from dermatological diseases, it is useful to apply pharmacological treatment, which is provided by psychiatry. Needless to say, psychiatry is also concerned with disorders which are primarily psychiatric, and the symptoms of which concern the skin (such as delusional parasitic diseases). However, assistance for individuals suffering from dermatological conditions also includes various psychotherapeutic approaches - ranging from the psychodynamic approach to the application of hypnosis, cognitive therapy, and behavioural therapy. Working with individuals suffering from dermatoses aims at facilitating struggling against difficulties and restrictions connected with medical conditions, and also becoming adjusted to them. It has also been found that psychotherapeutic interventions exert a favourable influence on the course of a disease, or even contribute to making the dermatological changes less acute, or to their remission (Miniszewska, 2010).

Psychodynamic influences result, among other things, in releasing suppressed feelings, gaining in- 
sight into, and becoming aware of the actual needs and wishes, and also in skilful differentiation between the real world and the world of the imagination. The objective of it is also to overcome reluctance to describe one's own state of health. Expressing threatening problems in a verbal form results in reducing their acuteness, or the disappearance of those problems. The applied therapeutic techniques include free associations, clarifications and confrontations, interpretations and working it out (Januszewski, 2001). From the point of view of psychoanalysis, the skin is the organ of expression of the various kinds of difficulties at the emotional level. The therapy consists in overcoming developmental or psychological conflicts and deficits, putting emphasis on the phenomenon of transference and countertransference. The most frequently applied techniques are the following: analysis, interpretation, and confrontation. That form of therapy is particularly recommended in cases in which, together with the medical condition, there are occurring personal problems the sources of which may be earlier traumatic experiences of a patient. Important here are the empathy and understanding of a therapist, as well as patience and analyzing the problem of a patient in the long-term perspective. The psychodynamic approach is concentrated, in connection with that, on the analysis of the current mental states of a patient and the genesis of them, and also searching for appropriate strategies which may be helpful in making them change. It is of use, among others, in the therapy of anxiety, depression or the low level of self-esteem, which frequently accompany medical conditions of the skin (Miniszewska, 2010).

In the literature, there are reports concerning curing diseases of the skin with the application of suggestion or hypnosis. Among others, Sheridan and Radmacher (1998) quote the descriptions of the cases of curing "ichthyosis" (congenital ichthyosiform erythroderma) or papillae with the application of suggestion. Shenefelt (2003) describes the application of relaxation, the techniques of coping with stress, suggestions concerning ceasing to scratch, and improving the condition of the skin, posthypnotic suggestions, and the techniques of strengthening the ego and maintaining peace in relation to 18 individuals affected by massive AD. As a result of those influences, the following were reduced: pruritus, scratching, problems with insomnia and strain. Frankel and Misch (quoting after Papadopoulos \& Bor, 1999) quote the case of a twenty-year old male individual suffering from psoriasis, the symptoms of which disappeared after the application of hypnosis and visualization. Suggestion and hypnosis strengthen the immunity of a person, and, ipso facto, may be helpful in treating medical conditions dependent on immunological mechanisms, such as nettle rash (Papadopoulos \& Bor, 1999).

There are numerous reports indicating the effectiveness of psychological intervention in treating dermatological conditions themselves. Attention, however, ought to be paid to the fact that the majority of the data originate from the descriptions of individual cases, or, alternatively, research conducted in small trials without control groups.

The cognitive approach, and the behavioural one, are applied more and more frequently for individuals affected by dermatological diseases, and they teach coping with specific minor medical problems (for example, pruritus) and restrictions by means of the introduction of the principles of self-monitoring, reducing harmful habits, distracting attention from minor medical problems, changing the convictions concerning the medical condition and one's own functioning, and teaching how to express emotions in a healthy and functional way. All of that may contribute to increasing the quality of life of affected individuals (Fortune et al., 2002; Fortune, Richards, Griffits, \& Main, 2004). The techniques proposed in this view include questioning mistakes in thinking, "the technique of the worst scenario", monitoring thoughts, keeping a diary, stopping thoughts, distracting attention, relaxation, memorizing the positive aspects of one's outside appearance and systematic desensitization. The objectives of cognitive-behavioural intervention are: 1) the affected individual becoming acquainted with and understanding their psycho-physical condition; 2) identifying and naming the symptoms being experienced, as well as the difficulties; 3) acquiring knowledge concerned with the possibilities of treatment; 4) facilitating making decisions concerning the affected individual undergoing treatment; 5) discussing the difficulties in contacts with other people; 6) the analysis of difficulties connected with the medical condition itself, and separating those factors and behaviours which strengthen them; 7) improvement in the image of one's own body and in self-esteem; 8) becoming aware of the erroneous convictions concerned with the medical condition, and the reformulation of them; 9) identification and strengthening the effective ways of coping already being applied; 10) identification of the possessed, while not yet taken advantage of, resources which are to improve coping with the medical condition; 11) becoming aware of the practical ways of coping with difficult situations (for example, with being persistently stared at by other people) and practising them thoroughly; and 12) becoming aware of psychological problems which do not have to be directly connected with the medical condition. The foundation of that therapy is making a patient acquainted with the model of the occurrence of disorders in the condition of the skin, in accordance with the opinion of which visible dermatological changes, and the consequences of them, result in the development of maladaptive reactions (Papadopoulos \& Bor, 1999).

Initially, the individuals affected by dermatological conditions do not realize that they are in the need of psychotherapy. The principal problem which 
they have is the condition of the skin, and they make efforts to change it. Most frequently, they only consult a psychotherapist when pharmacological treatment has failed to produce desired results, and the somatic condition and/or emotional problems make it difficult to function on a daily basis. Taking into consideration the complexity of problems connected with medical conditions, cohesive interdisciplinary influences need to be exerted (by a psychologist, psychiatrist, dermatologist and a nurse), and those also need to include such actions as education concerning the issue of the biological aspects of a given medical condition, and the treatment of it, teaching how to care about the skin, explaining the model of stress, assumptions of cognitive-behavioural therapy, teaching relaxation, identification of cognitive mistakes and developing the abilities in the field of coping, assertiveness, etc. (Fortune et al., 2004).

It is revealed to be important as well to form support groups for individuals suffering from medical conditions of the skin, which may help them in overcoming the rejection being experienced; such groups make it possible to share experiences, and to meet other affected people. The activity of support groups consists in education concerning the medical condition itself, and coping with it (Miniszewska, 2010).

\section{CONCLUSIONS}

Numerous aspects of the functioning of individuals suffering from medical conditions of the skin have long been the central subject of the interest of psychology. That is the case both for the origins of numerous dermatoses and for factors exacerbating their course and influencing their treatment. In addition, what is particularly significant for this group of diseases, is the social functioning of people affected by them, and it is another focus of interest of psychology as well. The objective of this paper was to propose a more interdisciplinary approach to psychodermatology, and to present a succinct review of the psychological aspects of diseases of the skin. Assisting individuals affected by dermatological diseases involves dermatology, psychiatry and psychology, which ought to support one another. In the area of psychology, it is recommendable to draw up records of actions taken in relation to individuals suffering from dermatological conditions, and also programmes aiming at the improvement of the functioning of individuals affected, and making them better adjusted to their medical condition.

\section{REFERENCES}

Basińska, M. A., \& Woźniewicz, A. (2012). Inteligencja emocjonalna chorych na łuszczycę jako wyznacznik akceptacji choroby [Emotional intelligence in psoriasis patients as a determinant of acceptance of illness]. Przegląd Dermatologiczny, 99, 202-209.

Basińska, M. A., \& Szymańska, L. (2013). Związek nastroju z cechami choroby u osób z łuszczycą [Relationship of mood with characteristics of the disease among a group of psoriasis patients]. Przeglad Dermatologiczny, 100, 146-143.

Ben-Gashir, M. A., Seed, P. T., \& Hay, R. J. (2004). Quality of life and disease severity are correlated in children with atopic dermatitis. British Journal of Dermatology, 150, 284-290.

Czubalski, K. (1983). Psychologiczne i psychosomatyczne aspekty chorób skóry a postępowanie lekarza dermatologa [Psychological and psychosomatic aspects of skin diseases and proceeding of a dermatologists ]. In: M. Jarosz (ed.), Psychologia lekarska [The medical psychology] (pp. 441-446). Warszawa: PZWL.

De Korte, J., Sprangers, M., Mombers, F., \& Bos, J. (2004). Quality of life in patients with psoriasis: A systematic literature review. The Journal of Investigative Dermatology, Symposium Proceedings, 9, 140-147.

Ehlers, A., Osen, A., Wenninger, K., \& Gieler, U. (1994). Atopic dermatis and stress: The possible role of negative communication with significant others. International Journal of Behavioral Medicine, 1, 107-112.

Fortune, D., Richards, H., Kirby, B., Bowcock, S., Main, C., \& Griffits, C. (2002). A cognitive-behavioral symptom management programme as an adjunct in psoriasis therapy. British Journal of Dermatology, 146, 458-465.

Fortune, D., Richards, H., Griffits, C., \& Main, C. J. (2004). Targeting cognitive-behavior therapy to patients implicit model of psoriasis: Results from a patient preference controlled trial. British Journal of Dermatology, 43, 65-82.

Frankel, F., \& Misch, R. (1973). Psoriasis and hypnosis. International Journal of Clinical Psychotherapy and Psychosomatics, 21, 121-123.

Gieler, U. (2003). Psyche and skin: What's new? Journal of the European Academy of Dermatology and Venereology, 17, 128-130.

Ginsburg, I. H. (1996). The psychosocial impact of skin disease. An overview. Dermatology Clinics, 14, 473-483.

Gupta, M. A., \& Gupta, A. K. (1996). Psychodermatology: An update. Journal of the American Academy of Dermatology, 34, 1030-1046.

Gupta, M. A., \& Gupta, A. K. (2001). The psychological comorbidity in acne. American Journal of Clinical Dermatology, 19, 360-363.

Gupta, M. A., \& Gupta, A. K. (2003). Psychiatric and psychological co-morbidity in patients with der- 
matologic disorders. American Journal of Clinical Dermatology, 4, 833-842.

Heszen, I., \& Sęk, H. (2012). Psychologia zdrowia [Health psychology]. Warszawa: PWN.

Jafferany, M. (2010). Psychodermatology: a guide to understand common psychocutaneous disorders. The Primary Care Companion to the Journal of Clinical Care Psychiatry, 9, 203-213.

Janowski, K. (2006). Osobowościowe uwarunkowania radzenia sobie ze stresem tuszczycy [Personality determinants of coping with the stress of psoriasis]. Lublin: Wydawnictwo Polihymnia.

Januszewska, E. (2001). Psychosomatyczne aspekty choroby skóry [Psychosomatic aspects of skin diseases]. In: L. Szewczyk \& A. Kulik (eds.), Wybrane zagadnienia z psychologii klinicznej i osobowości [Selected issues in clinical and personality psychology] (pp. 79-96). Lublin: TN KUL.

Janowski, K., Steuden, S., \& Bereza, B. (2014). The Polish version of Skindex-29: psychometric properties of an instrument to measure quality of life in dermatology. Postępy Dermatologii i Alergologii, 31, 1-9.

Janowski, K., Steuden, S., \& Bogaczewicz, J. (2014). Clinical and psychological characteristics of patients with psoriasis reporting various frequencies of pruritus. International Journal of Dermatology, 53, 820-829.

Januszewski, A. (2001). Podstawy i charakterystyczne elementy terapii psychoanalitycznej w chorobach skóry [Fundamentals and characteristic elements of psychoanalytic therapy for skin diseases]. In: L. Szewczyk \& A. Kulik (eds.), Wybrane zagadnienia z psychologii klinicznej i osobowości [Selected issues in clinical and personality psychology ] (pp. 97-117). Lublin: TN KUL.

Juszkiewicz-Borowiec, M. (1999). Udział stresu w etiopatogenezie wybranych chorób skóry [Participation of stress in the etiology of some skin diseases]. Przeglad Dermatologiczny, 86, 61-65.

Kadri, N. (2003). Dermatologia i psychiatria [Dermatology and psychiatry]. WPA Bulletin on Depression, 7, 17-22.

Koblenzer, P. (1996). A brief history of psychosomatic medicine. Dermatologic Clinics, 4, 395-397.

Korabel, H., Dudek, D., Jaworek, A., \& Wojas-Pelc, A. (2008). Psychodermatologia: psychologiczne i psychiatryczne aspekty w dermatologii [Psychodermatology: psychological and psychiatrical aspects of dermatology]. Przeglad Lekarski, 65, 244-248.

Koo, J., \& Lee, C. (2003). General approach to evaluating psychodermatological disorders. In: J. Y. M. Koo \& C. S. Lee (eds.), Psychocutaneous Medicine (pp. 1-29). New York: Marcel Dekker.

Koo, J., \& Pham, C. (1992). Psychodermatology: practical quidelines on pharmacotherapy. Archives of Dermatology, 126, 381-388.
Leon, A., Levin, E., \& Koo, J. (2013). Psychodermatology: an overview. Seminars of Cutaneous Medicine and Surgery, 32, 64-67.

Luban-Plozza, B., Pöldinger, W., Kröger, F., \& Wasilewski, B. (1995). Zaburzenia psychosomatyczne w praktyce lekarskiej [Psychosomatic disorders in medical practice]. Warszawa: PZWL.

Makowska, I., \& Gmitrowicz, A. (2014). Psychodermatologia - pogranicze dermatologii, psychiatrii i psychologii [Psychodermatology - the interface between dermatology, psychiatry and psychology]. Psychiatria i Psychologia Kliniczna, 14, 100-105.

Mercan, S., \& Kivanç Altunay, I. (2003). Psychodermatology: a collaborative subject of psychiatry and dermatology. Turkish Journal of Psychiatry, 17, 305-313.

Miniszewska, J. (2010). Psychologiczne aspekty chorób skóry - psychodermatologia [Psychological aspects of skin diseases - psychodermatology]. In: E. Zasępa (ed.), Choroba, niepetnosprawność, cierpienie oraz postawy wobec nich - w teorii i badaniach [Illness, disability, suffering and attitudes towards them - in theory and research] (pp. 230-244). Warszawa: Wyd. Akademii Pedagogiki Specjalnej.

Miniszewska, J., Chodkiewicz, J., Ograczyk, A., \& Zalewska, A. (2013). Optimism as a predictor of health related quality of life in psoriatics. Postępy Dermatologii i Alergologii, 2, 91-95.

Miniszewska, J., Juczyński, Z., Ograczyk, A., \& Zalewska, A. (2013). Health-related quality of life in psoriasis: important role of personal resources. ActaDermato-Venereologica, 93, 551-556.

Orion, E., Feldman, B., Ronni, W., \& Ben-Avi, O. (2012). A psychodermatology clinic the concept, the format, and our observations from Israel. American Journal of Clinical Dermatology, 13, 97-101.

Papadopoulos, L., \& Bor, R. (1999). Psychological Approaches to Dermatology. London: The British Psychological Society.

Panconesi, E. (2000). Psychosomatic dermatology: past and future. International Journal of Dermatology, 39, 732-734.

Picardi, A., Abeni, D., Melchi, C. F., Puddu, P., \& Pasquini, P. (2000). Psychiatric morbidity in dermatological outpatients: an issue to be recognized. British Journal of Dermatology, 143, 983-991.

Picardi, A., Abeni, D., Renzi, C., Braga, M., Melchi, C. F., \& Pasquini, P. (2003). Treatment outcome and incidence of psychiatric disorders in dermatological out-patients. Journal of the European Academy of Dermatology and Venereology, 17, 155-159.

Picardi, A., Amerio, P., Baliva, G., Barbieri, C., Teofolio, P., Bolli, S., Salvatori, V., Mazzotti, E., Pasquino, P., \& Abeni, D. (2004). Recognition of depressive and anxiety disorders in dermatological outpatients. Acta Dermato-Venerologica, 84, 213-217.

Poot, F., Sampogona, F., \& Onnis, L. (2007). Basic knowledge in psychodermatology. Journal of Eu- 
ropean Academy of Dermatology and Venereology, 21, 227-234.

Rabung, S., Schmidt, C., Hüther, G., \& Schauenburg, H. (2003). The influence of psychosocial stress on neuroimmunological parameters and skin conditions in a patient with atopic dermatitis. Dermatology and Psychosomatics, 4, 207-214.

Rodríguez-Cerdeira, C., Pera-Grasa, J., Molares, A., Isa-Isa, R., \& Arenas-Guzmán, R. (2011). Psychodermatology: past, present and future. The Open Dermatology Journal, 5, 21-27.

Joanna Miniszewska

Senra, M., \& Wollenberg, A. (2014). Psychodermatological aspects of atopic dermatitis. British Journal of Dermatology, 170, 38-43.

Shenefelt, P. (2003). Biofeedback, cognitive-behavioral methods, and hypnosis in dermatology: Is it all in your mind? Dermatologic Therapy, 16, 114-122.

Sheridan, Ch. L., \& Radmacher, S. A. (1998). Psychologia zdrowia. Wyzwanie dla biomedycznego modelu zdrowia [Health Psychology. Chalenging the biomedical model]. Warszawa: PTP.

Steuden, S., \& Janowski, K. (2001). Zastosowanie kwestionariusza Skindex do pomiaru jakości życia u pacjentów z łuszczycą [Application of Skindex questionnaire to measure the quality of life in patients with psoriasis]. Przegląd Dermatologiczny, 1, 41-48.

Steuden, S., \& Janowski, K. (2000). Choroby dermatologiczne a zaburzenia psychiczne [Dermatological diseases and mental disorders]. Przeglad Dermatologiczny, 3, 257-261.

Steuden, S., \& Janowski, K. (2002). Schorzenia psychodermatologiczne [Psychodermatologic disorders]. Przegląd Dermatologiczny, 3, 175-183.

Steuden, S., Okła, W., \& Puchalska, K. (2006). Lęk jako zmienna modyfikująca poczucie jakości życia u osób chorych na łuszczycę [Anxiety as a variable modifying the quality of life in patients with psoriasis]. In: S. Steuden \& W. Okła (eds.), Jakość życia w chorobie [Quality of life in illness] (pp. 63-84). Lublin: Wydawnictwo KUL.

Szepietowski, J. (2011). Przedmowa [Rreface]. In: T. Rzepa, J. Szepietowski, \& R. Żaba (eds.), Psychologiczne i medyczne aspekty chorób skóry [Psychological and medical aspects of skin disease] (pp. 52-64). Wrocław: Wydawnictwo Cornetis.

Walker, C., \& Papadopoulos, L. (2005). Psychodermatology. The psychological impast of skin disorders. Cambrige: Cambrige University Press.

Świrszcz, K., \& Schier, K. (2002). Związek między psychiką i chorobą somatyczną na przykładzie atopowego zapalenia skóry [The relationship between psyche and somatic disease on the example of atopic dermatitis]. Psychiatria i Psychologia Kliniczna, 2, 127-137.

Tuszyńska-Bogucka,V., Czelej, D., Lecewicz-Toruń, B., \& Krasowska, D. (2002). Profil osobowości oraz nasilenie przeżyć o charakterze lękowym u pa- cjentów z atopowym zapaleniem skóry [Personality profile and severity of an anxiety experiences in patients with atopic dermatitis]. Przeglad Dermatologiczny, 6, 469-475.

Walker, C., \& Papadopoulos, L. (2005). Psychodermatology: The Psychological Impact of Skin Disorders. London: Cambridge University Press.

Yadav, S., Narang, T., \& Kumaran, M. (2013) Psychodermatology: A comprehensive review. Indian Journal of Dermatology and Venereology, 79, 176192. 